\title{
Influence of Annealing Temperature on Weak-Cavity Top-Emission Red Quantum Dot Light Emitting Diode
}

\author{
Chun-Yu Lee ${ }^{1}$, Ya-Pei Kuo ${ }^{1}$, Peng-Yu Chen ${ }^{1}$, Hsieh-Hsing Lu ${ }^{1}$ and Ming Yi Lin ${ }^{2, *(1)}$ \\ 1 AU Optronics Corporation, Hsinchu 30078, Taiwan; d92941010@ntu.edu.tw (C.-Y.L.); \\ joanne.kuo@auo.com (Y.-P.K.); kevinplus2012@gmail.com (P.-Y.C.); d99941004@gmail.com (H.-H.L.) \\ 2 Department of Electrical Engineering, National United University, Miaoli 36003, Taiwan \\ * Correspondence: mylin@nuu.edu.tw
}

Received: 27 October 2019; Accepted: 15 November 2019; Published: 19 November 2019

\begin{abstract}
In this report, we show that the annealing temperature in QDs/Mg-doped $\mathrm{ZnO}$ film plays a very important role in determining QLEDs performance. Measurements of capacitance and single carrier device reveal that the change of the device efficiency with different annealing temperatures is related to the balance of both electron and hole injection. A comparison of annealing temperatures shows that the best performance is demonstrated with $150{ }^{\circ} \mathrm{C}$-annealing temperature. With the improved charge injection and charge balance, a maximum current efficiency of $24.81 \mathrm{~cd} / \mathrm{A}$ and external quantum efficiency (EQE) of $20.09 \%$ are achievable in our red top-emission QLEDs with weak microcavity structure.
\end{abstract}

Keywords: QLEDs; top-emission; microcavity

\section{Introduction}

Colloidal semiconductor quantum dots (QDs) have attracted extensive attention as candidates for next-generation display application owing to their unique properties, such as high color purity, narrow full width at half-maximum (FWHM), high photoluminescence quantum yield (PLQY), and simple fabrication process [1-12]. A number of approaches for fabrication of cadmium-based QD light-emitting diodes (QLEDs) have been demonstrated, including device structure, material synthesis, and ligand exchange [13-21]. However, most of researches are based on bottom-emission structure. For the display applications, top-emission structure is becoming increasingly important. It is because of that top-emission structure has favorable attributes for improving display performance, which include vesting the freedom of pixel and circuit design, increasing the aperture ratio, and lowering power consumption [22]. In this paper, we utilized red top-emission QLED (made by using the all solution-processed device structure) with indium zinc oxide (IZO) as top electrode. To attain excellent device performances and high luminescence efficiency, the device contains emitting layer of $\mathrm{CdZnSe} / \mathrm{ZnS}$ core/shell QDs with Mg-doped $\mathrm{ZnO}$ nanoparticle as the electron transporting layer (ETL) and stacked organic hole transporting layer (HTL). Furthermore, we investigate the impact of thermal annealing on the carrier densities and device performances. It is worth noting that the fabricated QLED reveals an impressive current efficiency of $24.81 \mathrm{~cd} / \mathrm{A}$ and external quantum efficiency (EQE) of $20.09 \%$ with a color co-ordinate $(0.687,0.309)$, which is the highest performance ever reported in red top-emission QLED structure with IZO electrode. 


\section{Materials and Methods}

In this report, reference QLED device layer structure consists of a patterned ITO/Ag/ITO glass (Top ITO: $12 \mathrm{~nm}$ thick; Ag layer is to reflect light to top electrode), a HIL (20 nm thick), HTL (23 nm thick), QD EML (11 nm thick), ETL (36 nm thick), and IZO cathode (185 nm thick) as schematically shown in Figure 1a. The device is weak microcavity structure, which could effectively eliminate the microcavity effect and enable angular color stability for display applications. To attenuate the optical microcavity effect, a high transparent IZO top contact with a room temperature and low power sputtering process is employed. Figure $1 \mathrm{~b}$ shows the optical transmittance of the IZO $(185 \mathrm{~nm})$ deposited on the glass substrate. The average transmittance in visible range $(400-700 \mathrm{~nm})$ is above $80 \%$, which is agreed with the previous reported results $[23,24]$. It means that the microcavity is weakly formed by the ITO/Ag/ITO anode mirror and IZO cathode. HIL and HTL are the materials for the commercial product of organic light-emitting diodes (OLED). HIL is composed of PFSA (tetrafluoroethylene-perfluoro-3,6-dioxa-4-methyl-7-octenesulphonic acid copolymer), PEDOT:PSS (Poly(3,4-ethylenedioxythiophene)-poly(styrenesulfonate)), and dimethyl sulfoxide. HTL is poly[(9,9-dioctylfluorenyl-2,7-diyl)-co-(4,4'-(N-(4-sec-butylphenyl)diphenylamine)] (TFB) derivative. Red QDs and $\mathrm{Zn}_{0.85} \mathrm{Mg}_{0.15} \mathrm{O}$ nanoparticles (NPs) are purchased from Mesolight Inc (China). The PLQY of QDs is 70\%. Here, $\mathrm{Zn}_{0.85} \mathrm{Mg}_{0.15} \mathrm{O}$ is $\mathrm{Mg}$-doped $\mathrm{ZnO}$ NPs for efficient electron transport and easy injection in the red QDs EML layer.
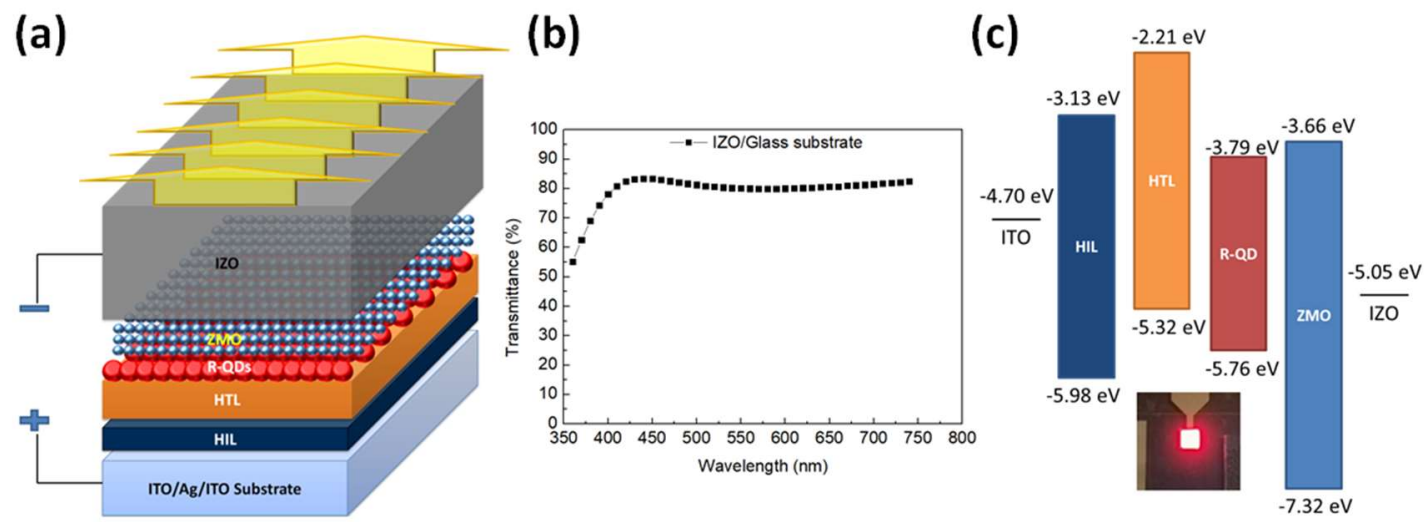

Figure 1. (a) Schematic of the device structure. (b) Optical transmittance of the IZO/glass substrate. (c) Energy band diagram of the red top-emission QLEDs. The inset is a photograph of the working device.

All the QLED devices are fabricated in the nitrogen-filled glove box. First, we clean the ITO/Ag/ITO substrate by de-ionized water, acetone, and isopropyl alcohol in ultrasonic for 25 min sequentially and then the substrate is treated under UV ozone for $15 \mathrm{~min}$ to increase the work function and to improve the adhesion to HIL. Then, HIL is spin-coated at $910 \mathrm{rpm}$ on the ITO/Ag/ITO substrate and baked at $230{ }^{\circ} \mathrm{C}$ for $15 \mathrm{~min}$. HTL is spin-coated at $3700 \mathrm{rpm}$ and baked at $230{ }^{\circ} \mathrm{C}$ for $30 \mathrm{~min}$. After that, red QDs and $\mathrm{Zn}_{0.85} \mathrm{Mg}_{0.15} \mathrm{O}$ NPs are deposited layer-by-layer via spin casting on the HTL/HIL/substrate. The red QDs and $\mathrm{Zn}_{0.85} \mathrm{Mg}_{0.15} \mathrm{O}$ NPs layers are spin-casted both at $3000 \mathrm{rpm}$. Finally, the transparent IZO top-electrode is deposited by sputtering under a based vacuum of $10^{-7}$ torr. All devices are encapsulated in a glass-to-glass epoxy sealed package with desiccant. The emitting area is $2 \times 2 \mathrm{~mm}$. Figure $1 \mathrm{c}$ shows the schematic diagram of fabricated red top-emission QLED structure with energy band/level diagram of each layer. The electronic energy levels are investigated by ultraviolet photoemission spectroscopy (UPS) in a Kratos AXIS ultra-DLD ultrahigh vacuum photoemission spectroscopy system with HeI excitation.

The corresponding cross-sectional electron transmission microscopy (TEM) image of our QLEDs is shown in Figure 2. The figure clearly shows that a compact QD emitting layer is placed between charge carrier transport layers. 


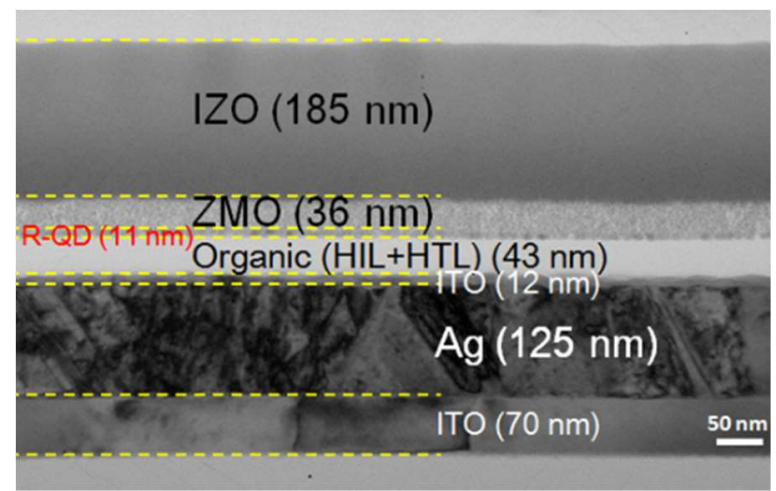

Figure 2. Cross-sectional transmission electron microscopy image of the red top-emission QLEDs.

\section{Results and Discussion}

In the experiment, to investigate the thermal annealing on the red top-emission QLEDs, we fabricated four QLEDs at different annealing temperatures of $100,150,200$, and $200{ }^{\circ} \mathrm{C}$ for 10 min respectively after $\mathrm{Zn}_{0.85} \mathrm{Mg}_{0.15} \mathrm{O}$ NPs layers are deposited on the QDs layers. In addition, the recipe of $100^{\circ} \mathrm{C}$ annealing temperatures has been widely used in QLED fabrication [16-18]. Figure 3 shows the EL performance of fabricated QLEDs. As J-V characteristics demonstrated in Figure 3a, current density is raised with increasing temperature. It is important to note that with high temperature annealing $\left(>100{ }^{\circ} \mathrm{C}\right)$, the current densities of the QLED devices are higher than that of the device with $100{ }^{\circ} \mathrm{C}$ annealing. When the annealing temperature is raised to 150 and $200{ }^{\circ} \mathrm{C}$, the QLED devices have nearly 1.75 and 5.5-fold higher current density than that annealed at $100{ }^{\circ} \mathrm{C}$ at the same driving voltage of $6 \mathrm{~V}$, respectively. In contrast, for the device with $250{ }^{\circ} \mathrm{C}$-annealing temperature, the current density is only 1.2 -fold higher than that of the device annealed at $100{ }^{\circ} \mathrm{C}$. We attribute this phenomenon to the carrier mobility changed depending on the annealing temperatures. In other words, high annealing temperature $\left(>100{ }^{\circ} \mathrm{C}\right)$ can improve carrier mobility of QDs/ $\mathrm{Zn}_{0.85} \mathrm{Mg}_{0.15} \mathrm{O}$ $\mathrm{O}$ film. Figure $3 \mathrm{~b}-\mathrm{d}$ demonstrate the luminescence-current density (L-J) characteristics and current efficiency-luminescence-EQE properties of these devices. As shown in Figure $3 \mathrm{~b}$, the highest luminescence-current density curve is observed at $150{ }^{\circ} \mathrm{C}$ annealing temperature. When annealing temperature is increased to $200^{\circ} \mathrm{C}$, the luminescence-current density curve of the QLED device starts to decrease. In particular, as the annealing temperature is further raised to $250{ }^{\circ} \mathrm{C}$, the luminescence significantly decreased. These results suggest that the high temperature degradation of QDs occurred. Figure 3c,d show the current efficiency and EQE of QLEDs, revealing that the best performance is obtained at annealing temperature of $150{ }^{\circ} \mathrm{C}$; it reaches the highest current efficiency of $24.81 \mathrm{~cd} / \mathrm{A}$ and EQE of $20.09 \%$ with a color co-ordinate $(0.687,0.309)$. Moreover, the devices with annealing temperature of 200 and $250{ }^{\circ} \mathrm{C}$ exhibit dramatic decrease in device efficiency. It is clear that the device with $250^{\circ} \mathrm{C}$ annealing temperature has the poorest current efficiency of $1.54 \mathrm{~cd} / \mathrm{A}$ and EQE of $1.15 \%$. The $\mathrm{QDs} / \mathrm{Zn}_{0.85} \mathrm{Mg}_{0.15} \mathrm{O}$ film presents dramatic difference in the device efficiency depending on the annealing temperature. We speculate that the change of the device efficiency is closely related to the balance of both electron and hole injection. The EL spectra of QLEDs are shown in Figure 3e. It is found that the peak wavelength $(628 \mathrm{~nm})$ and full-width at half-maximum (FWHM) did not change any more and these devices showed similar CIE properties (see Figure 3f). Owing to Commission Internationale de L'Eclairage (CIE) 1931 color coordinates of $(0.687,0.309)$ and a narrow FWHM of $26 \mathrm{~nm}$, the color-saturation makes this red top-emission QLED an ideal red array for display application. The detailed EL performance of all red top-emission QLED devices are summarized in Table 1. 
(a)

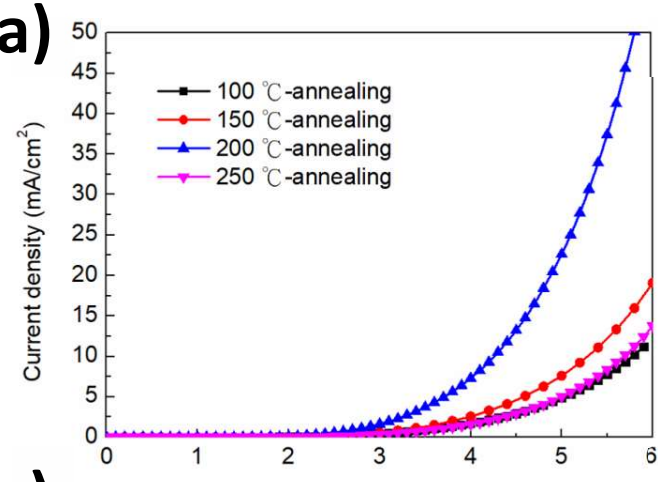

(c)
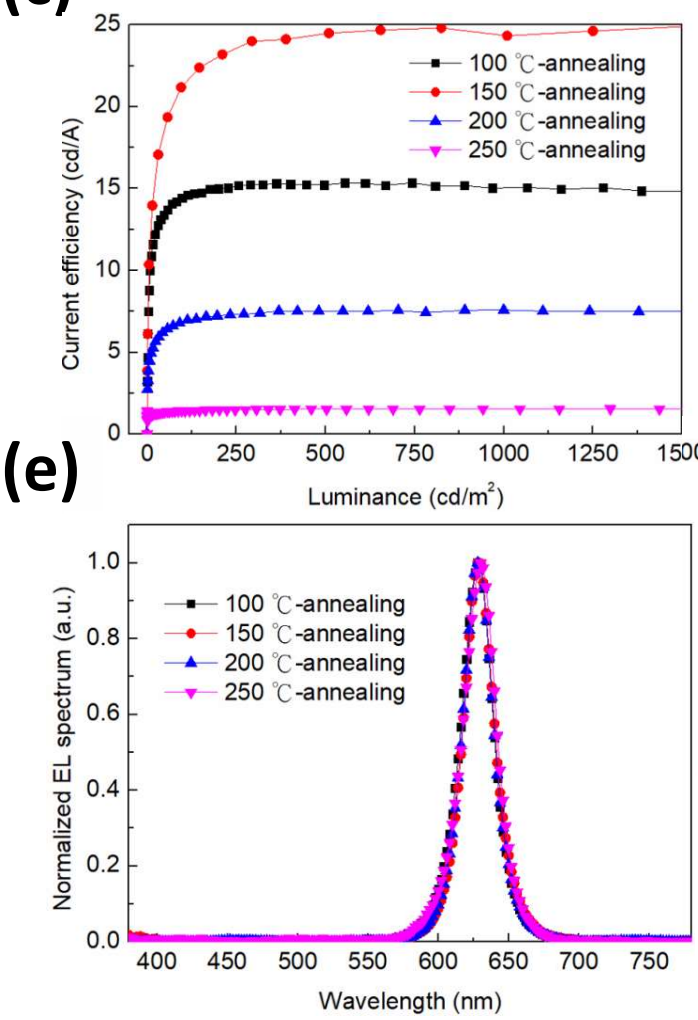

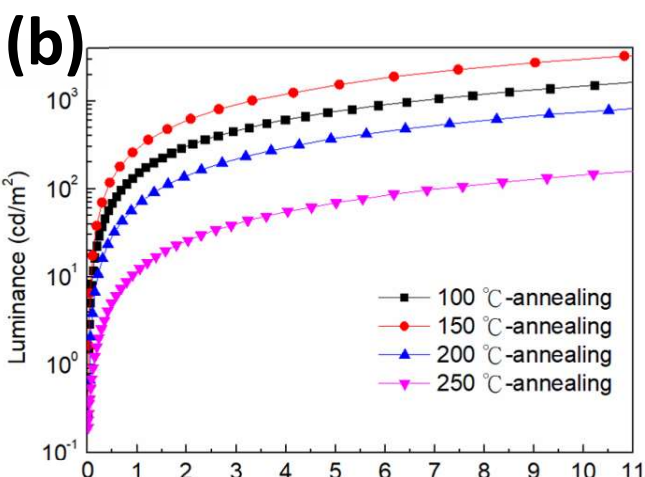

(d)
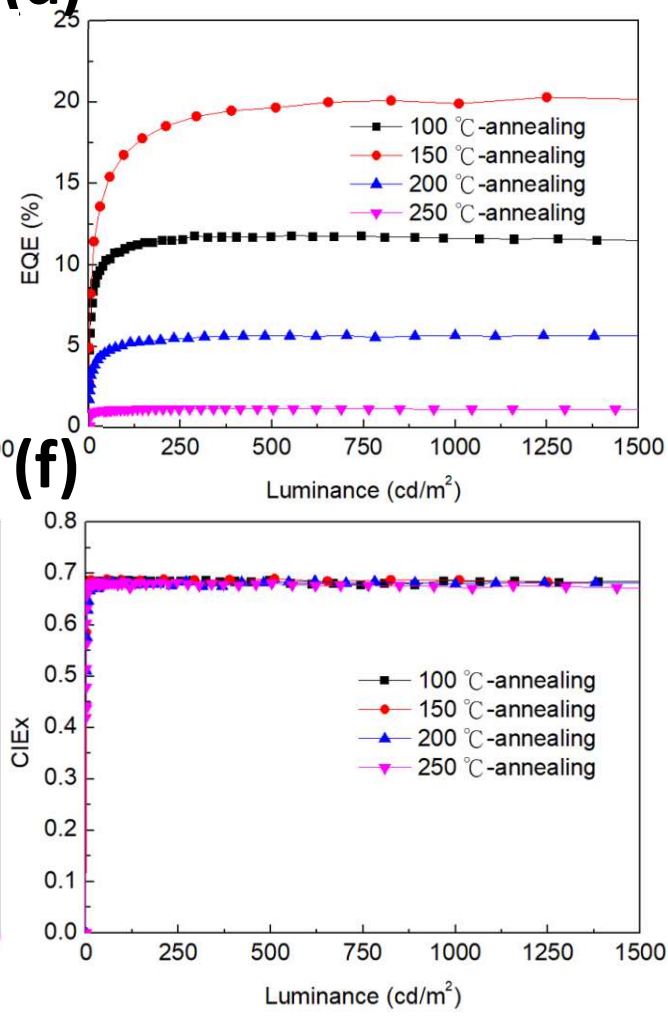

Figure 3. Device performance of the red top-emission QLEDs at different anneal temperatures. (a) Current density-voltage (J-V) characteristics. (b) Luminance-current density (L-J) characteristics. (c) Current efficiency-luminance characteristics. (d) EQE-luminance characteristics. (e) Normalized EL spectra. (f) CIEx-luminance characteristics.

Table 1. Summaries of 1931 CIE (x,y) chromaticity coordinates, electroluminescence emission peak wavelength $\lambda_{\max }$, FWHM, turn on voltage $V_{T}$, current efficiency $\eta_{A}$, and external quantum efficiency $\eta_{\mathrm{EQE}}$ of the red top-emission QLEDs at different anneal temperatures. Turn on voltage is measured at $1 \mathrm{~cd} / \mathrm{m}^{2}$.

\begin{tabular}{cccccccc}
\hline \multirow{2}{*}{$\begin{array}{c}\text { Weak-Cavity Top-Emission } \\
\text { R-QLED }\end{array}$} & $\mathbf{x}$ & $\mathbf{y}$ & Peak & FWHM & $\mathbf{V}_{\mathbf{T}}$ & CE $\left(\boldsymbol{\eta}_{\mathbf{A}}\right)$ & EQE $\left(\eta_{\text {EQE }}\right)$ \\
\cline { 2 - 8 } & - & - & $\mathbf{n m}$ & $\mathbf{n m}$ & $\mathbf{V}\left[\mathbf{1} \mathbf{c d} / \mathbf{m}^{\mathbf{2}}\right]$ & $\mathbf{c d} / \mathbf{A}$ & $\%$ \\
\hline $\mathbf{1 0 0}{ }^{\circ} \mathbf{C}$-annealing & 0.684 & 0.311 & 628 & 26 & 1.9 & 15.1 & 11.6 \\
$\mathbf{1 5 0}{ }^{\circ} \mathbf{C}$-annealing & 0.687 & 0.307 & 628 & 26 & 1.9 & 24.8 & 20.1 \\
$\mathbf{2 0 0}$ C-annealing & 0.680 & 0.313 & 628 & 25 & 1.8 & 7.6 & 5.7 \\
$\mathbf{2 5 0}^{\circ} \mathbf{C}$-annealing & 0.671 & 0.313 & 628 & 27 & 2.6 & 1.5 & 1.2 \\
\hline
\end{tabular}

To evaluate the charge balance in our red QLED, we measure the capacitance-voltage $(\mathrm{C}-\mathrm{V})$ characteristics of all devices after annealing for different temperatures of $100,150,200$, and $250{ }^{\circ} \mathrm{C}$. 
Figure 4 shows the $\mathrm{C}-\mathrm{V}$ characteristics of the QLEDs. In order to minimize the contribution from traps, the modulating frequency at $100 \mathrm{KHz}$ is used. By doing so, we are able to obtain smooth $\mathrm{C}-\mathrm{V}$ curves. When a DC bias voltage is applied, a charge-unbalanced device will initiate the fast charge first, resulting in capacitance rise. In a QLED device, the electron mobility is generally higher than the hole mobility. Therefore, the electron injection starts and the injected electrons may accumulate at the interface of QD/HTL. The capacitance of the QLED devices with $100{ }^{\circ} \mathrm{C}$ annealing temperature rises at $2.2 \mathrm{~V}$, which means that the HTL is the only layer remaining depleted and other layers have reached flat band and charge injection. At a DC bias voltage of around $4.6 \mathrm{~V}$, the capacitance starts to decrease sharply. It indicates that the efficient radiative recombination of electrons and holes occurred, which is corresponding to the relaxation of accumulated carriers. For the device with $150{ }^{\circ} \mathrm{C}$ annealing temperature, the transition voltage corresponding to peak capacitance is unchanged and the peak capacitance is increased to $1.73 \mathrm{nF}$. These results represent that the charge injection is enhanced. This phenomenon means that an increase of capacitance resulted from efficient injection of both electrons and holes. When annealing temperature is increased to $200^{\circ} \mathrm{C}$, the transition voltage decreases to $1.5 \mathrm{~V}$ and peak capacitance increases to $1.79 \mathrm{nF}$. The decreasing voltage represents that the injection of slow carrier (holes) is enhanced. Moreover, the significantly increased peak capacitance implies that the charge accumulation is enlarged, leading to a more serious charge unbalance. In this case, we can conclude that the carrier increases in electron is much higher than that in holes. For the device further annealing at $250{ }^{\circ} \mathrm{C}$, the transition voltage shifts to $2.45 \mathrm{~V}$ and the capacitance peaks at $1.81 \mathrm{nF}$. The big shift of transition voltage is caused by the degradation of slow charge (holes) injection. Furthermore, the increased capacitance confirms that the electron injection is more efficient than hole injection, and the charge accumulation is highly pronounced.

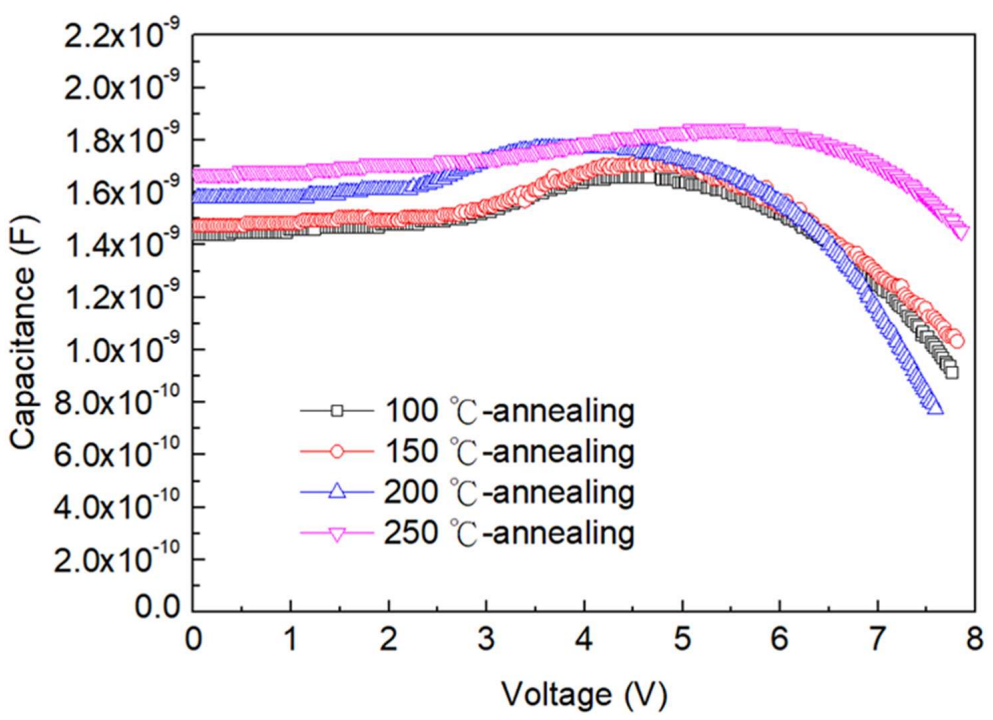

Figure 4. The capacitance-voltage characteristics of the red top-emission QLEDs at different anneal temperatures.

In order to further verify that the increased capacitance is related to the change of the charge injections between electrons and holes by thermal annealing, we prepared the single carrier devices of electron-only devices and hole-only devices and investigated their injection characteristics as described in Figure 5. The electron and hole currents are measured using the devices consisting of ITO/Zn ${ }_{0.85} \mathrm{Mg}_{0.15} \mathrm{O} / \mathrm{QDs} / \mathrm{Liq} / \mathrm{Al}$ (EOD) and ITO/HIL/HTL/QDs/HATCN/Al (HOD) with different annealing temperatures of $100,150,200$, and $200{ }^{\circ} \mathrm{C}$. We also calculated the mobility values from SCLC (space charge limited current) measurements. The current density versus voltage (or electric field) relationship in SCLC region can be expressed by the following equation: 


$$
J=\frac{9}{8} \varepsilon \varepsilon_{0} \frac{E^{2}}{d} \mu_{0} \exp (\beta \sqrt{E}),
$$

where $\mu$ is mobility of the current carrier, $\mu_{0}$ is zero-field mobility, $\varepsilon$ is relative permittivity, $\varepsilon_{0}$ is vacuum permittivity $\left(8.854 \times 10^{-14} \mathrm{~F} / \mathrm{cm}\right)$, and $\beta$ is Poole-Frenkel factor. The mobility values are summarized in Table 2. For the electron only device, the electron injection increases in a large range with the increase in annealing temperature. It is likely due to the improvement of $Z_{0.85} \mathrm{Mg}_{0.15} \mathrm{O}$ conductivity that resulted from reduced $\mathrm{ZnO}$ defect densities. For the hole only device, when the annealing temperature is raised from 100 to $200^{\circ} \mathrm{C}$, the hole current is also increased with the increase in annealing temperature. It can be seen that with $150{ }^{\circ} \mathrm{C}$ annealing temperature, holes in the current shows the comparable increase with electrons current. Hence, the carrier accumulation behavior is similar as that of the device with $100{ }^{\circ} \mathrm{C}$ annealing temperature. This indicates that the improvement in holes and electrons current simultaneously may result in enhanced device efficiency. However, with $200{ }^{\circ} \mathrm{C}$ annealing temperature the increased range in the holes current of HOD is much less than the electrons current of EOD. Therefore, the carrier accumulation is enhanced and resulted in the low device efficiency. For the HOD with $250{ }^{\circ} \mathrm{C}$ annealing temperature, the hole current shows a notable decrease compared with the devices with 150 and $200^{\circ} \mathrm{C}$ annealing temperature. The great decreasing hole current indicates that the unbalanced charge is further increased. As a consequence, the device presents the worst EL performance. These measurements of single carrier current also are in agreement with the mobility calculations. As shown in Table $2, \mu_{\mathrm{e}} / \mu_{\mathrm{h}}$ shows the minimum value of 12.2 at $150{ }^{\circ} \mathrm{C}$ annealing temperature. It indicates that optimization of the mobility is critical to achieving charge balance in QLEDs for high device performance. The above results are consistent with the measurements of EL and $\mathrm{C}-\mathrm{V}$ characteristics in Figures 3 and 4. Consequently, we believe that an applicable annealing temperature is important to achieving charge balance in QLED which is essential for high performance devices.

(a)

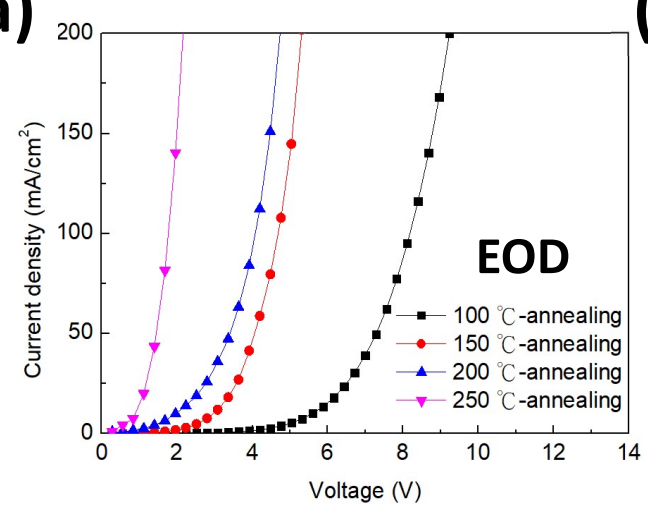

(b)

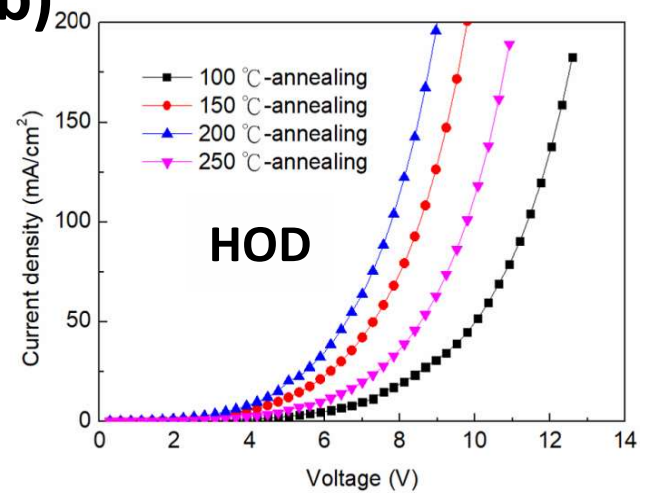

Figure 5. Current density-voltage (J-V) characteristics of (a) electron-only devices and (b) hole-only devices at different anneal temperatures.

Table 2. Electron and hole mobility for single carrier devices at different anneal temperatures.

\begin{tabular}{ccccc}
\hline Unit: $\mathbf{~ c m}^{\mathbf{2}} \mathbf{V}^{\mathbf{- 1}} \mathbf{~}^{\mathbf{- 1}}$ & $\mathbf{1 0 0}{ }^{\circ} \mathbf{C}$-annealing & $\mathbf{1 5 0}{ }^{\circ} \mathbf{C}$-annealing & $\mathbf{2 0 0}^{\circ} \mathbf{C}$-annealing & $\mathbf{2 5 0}{ }^{\circ} \mathbf{C}$-annealing \\
\hline Electron Mobility $\left(\boldsymbol{\mu}_{\mathrm{e}}\right)$ & $2.1 \times 10^{-7}$ & $1.2 \times 10^{-6}$ & $2.5 \times 10^{-6}$ & $9.4 \times 10^{-6}$ \\
Hole Mobility $\left(\boldsymbol{\mu}_{\mathbf{h}}\right)$ & $4.2 \times 10^{-9}$ & $9.8 \times 10^{-8}$ & $1.2 \times 10^{-7}$ & $4.2 \times 10^{-9}$ \\
$\boldsymbol{\mu}_{\mathrm{e}} / \boldsymbol{\mu}_{\mathrm{h}}$ & 50.0 & 12.2 & 20.8 & 2238.1 \\
\hline
\end{tabular}

\section{Conclusions}

In conclusion, a facile but effective method is proposed to improve the performance of quantum dot light-emitting diode (QLED) by tuning the charge injection between holes and electrons. It is found that the charge injection and device performance are dependent on the annealing temperature 
used in fabricating the QLED devices. By using an appropriate annealing temperature of $150{ }^{\circ} \mathrm{C}$, we achieved a very high current efficiency of $24.81 \mathrm{~cd} / \mathrm{A}$ in our red top-emission QLEDs with weak microcavity structure. The investigations on the capacitance-voltage characteristics and the single carrier measurements confirm that much improved electroluminescent efficiency originates from the significant enhancement of charge injection and charge balance.

Author Contributions: Conceptualization, M.Y.L.; formal analysis, Y.-P.K., P.-Y.C. and H.-H.L.; investigation, M.Y.L. and C.-Y.L.; data curation, C.-Y.L.; writing-original draft preparation, M.Y.L. and C.-Y.L.

Funding: This research was funded by the Ministry of Science and Technology (Taiwan), No. MOST 108-2221-E-239-010-.

Acknowledgments: This work was supported by the Ministry of Science and Technology of Taiwan, AU Optronics Corporation and National United University.

Conflicts of Interest: The authors declare no conflict of interest.

\section{References}

1. Pan, J.; Wei, C.; Wang, L.; Zhuang, J.; Huang, Q.; Su, W.; Nathan, A.; Lei, W.; Chen, J. Boosting the efficiency of inverted quantum dot light-emitting diodes by balancing charge densities and suppressing exciton quenching through band alignment. Nanoscale 2018, 10, 592-602. [CrossRef] [PubMed]

2. Mashford, B.S.; Stevenson, M.; Popovic, Z.; Hamilton, C.; Zhou, Z.; Breen, C.; Steckel, J.; Bulovic, V.; Bawendi, M.; Coe-Sullivan, S.; et al. High-efficiency quantum-dot light-emitting devices with enhanced charge injection. Nat. Photonics 2013, 7, 407. [CrossRef]

3. Liu, S.; Liu, W.; Ji, W.; Yu, J.; Zhang, W.; Zhang, L.; Xie, W. Top-emitting quantum dots light-emitting devices employing microcontact printing with electricfield-independent emission. Sci. Rep. 2016, 6, 22530. [CrossRef] [PubMed]

4. $\quad$ Liang, H.; Luo, Z.; Zhu, R.; Dong, Y.; Lee, J.H.; Zhou, J.; Wu, S.T. High efficiency quantum dot and organic LEDs with a back-cavity and a high index substrate. J. Phys. D Appl. Phys. 2016, 49, 145103. [CrossRef]

5. Yang, X.; Dev, K.; Wang, J.; Mutlugun, E.; Dang, C.; Zhao, Y.; Liu, S.; Tang, Y.; Tan, S.T.; Sun, X.W.; et al. Light Extraction Efficiency Enhancement of Colloidal Quantum Dot Light-Emitting Diodes Using Large-Scale Nanopillar Arrays. Adv. Funct. Mater. 2014, 24, 5977-5984. [CrossRef]

6. Wang, F.; Sun, W.; Liu, P.; Wang, Z.; Zhang, J.; Wei, J.; Li, Y.; Hayat, T.; Alsaedi, A.; Tan, Z. Achieving Balanced Charge Injection of Blue Quantum Dot Light-Emitting Diodes through Transport Layer Doping Strategies. J. Phys. Chem. Lett. 2019, 10, 960-965. [CrossRef]

7. Small, C.E.; Tsang, S.W.; Kido, J.; So, S.K.; So, F. Origin of enhanced hole injection in inverted organic devices with electron accepting interlayer. Adv. Funct. Mater. 2012, 22, 3261-3266. [CrossRef]

8. Frecker, T.; Bailey, D.; Arzeta-Ferrer, X.; McBride, J.; Rosenthal, S.J. Quantum dots and their application in lighting, displays, and biology. ECS J. Solid State Sci. Technol. 2016, 5, R3019-R3031. [CrossRef]

9. Moon, H.; Lee, C.; Lee, W.; Kim, J.; Chae, H. Stability of Quantum Dots, Quantum Dot Films, and Quantum Dot Light-Emitting Diodes for Display Applications. Adv. Mater. 2019, 31, 1804294. [CrossRef]

10. Bai, J.; Chang, C.; Wei, J.; Dong, C.; Peng, H.; Jin, X.; Zhang, Q.; Li, F.; Li, Q. High efficient light-emitting diodes with improved the balance of electron and hole transfer via optimizing quantum dot structure. Opt. Mater. Express 2019, 9, 3089-3097. [CrossRef]

11. Su, Q.; Sun, Y.; Zhang, H.; Chen, S. Origin of Positive Aging in Quantum-Dot Light-Emitting Diodes. Adv. Sci. 2018, 5, 1800549. [CrossRef] [PubMed]

12. Pan, J.; Chen, J.; Huang, Q.; Khan, Q.; Tao, X.L.Z.; Zhang, Z.; Lei, W.; Nathan, A. Size tunable ZnO nanoparticles to enhance electron injection in solution processed QLEDs. ACS Photonics 2016, 3, $215-222$. [CrossRef]

13. Wang, L.; Lv, Y.; Lin, J.; Fan, Y.; Zhao, J.; Wang, Y.; Liu, X. High-efficiency inverted quantum dot light-emitting diodes with enhanced hole injection. Nanoscale 2017, 9, 6748-6754. [CrossRef] [PubMed]

14. Liang, F.; Liu, Y.; Hu, Y.; Shi, Y.; Liu, Y.; Wang, Z.; Wang, X.; Sun, B.; Liao, L. Polymer as an additive in the emitting layer for high-performance quantum dot light-emitting diodes. ACS Appl. Mater. Interfaces 2017, 9, 20239-20246. [CrossRef] [PubMed] 
15. Choi, S.; Moon, J.; Cho, H.; Kwon, B.H.; Cho, N.S.; Lee, H. Partially pyridine-functionalized quantum dots for efficient red, green, and blue light-emitting diodes. J. Mater. Chem. C 2019, 7, 3429-3435. [CrossRef]

16. Ippen, C.; Guo, W.; Zehnder, D.; Kim, D.; Manders, J.; Barrera, D.; Newmeyer, B.; Hamilton, D.; Wang, C.; Hotz, C.; et al. High efficiency heavy metal free QD-LEDs for next generation displays. J. Soc. Inf. Display 2019, 27, 338-346. [CrossRef]

17. Chrzanowski, M.; Banski, M.; Sitarek, P.; Misiewicz, J.; Podhorodecki, A. Quantum-dot light-emitting diode with ultrathin Au electrode embedded in solution-processed phosphomolybdic acid. RSC Adv. 2019, 9, 10754-10759. [CrossRef]

18. Chen, S.; Cao, W.; Liu, T.; Tsang, S.W.; Yang, Y.; Yan, X.; Qian, L. On the degradation mechanisms of quantum-dot light-emitting diodes. Nat. Commun. 2019, 10, 765. [CrossRef]

19. Li, X.; Zhao, Y.B.; Fan, F.; Levina, L.; Liu, M.; Quintero-Bermudez, R.; Gong, X.; Quan, L.N.; Fan, J.; Yang, Z.; et al. Bright colloidal quantum dot light-emitting diodes enabled by efficient chlorination. Nat. Photonics 2018, 12, 159. [CrossRef]

20. Qian, L.; Zheng, Y.; Xue, J.; Holloway, P.H. Stable and efficient quantum-dot light-emitting diodes based on solution-processed multilayer structures. Nat. Photonics 2011, 5, 543. [CrossRef]

21. Cao, W.; Xiang, C.; Yang, Y.; Chen, Q.; Chen, L.; Yan, X.; Qian, L. Highly stable QLEDs with improved hole injection via quantum dot structure tailoring. Nat. Commun. 2018, 9, 2608. [CrossRef] [PubMed]

22. Tang, Z.; Lin, J.; Wang, L.; Lv, Y.; Hu, Y.; Fan, Y.; Guo, X.; Zhao, J.; Wang, Y.; Liu, X. High performance, top-emitting, quantum dot light-emitting diodes with all solution-processed functional layers. J. Mater. Chem. C 2017, 5, 9138-9145. [CrossRef]

23. Kang, J.; Jeong, W.; Kim, J.; Kim, H.; Kim, D.; Lee, G. High-Performance Flexible Organic Light-Emitting Diodes Using Amorphous Indium Zinc Oxide Anode. Electrochem. Solid State Lett. 2007, 10, J75-J78. [CrossRef]

24. Kim, H.; Lee, K.; Kwon, J.H. Transparent indium zinc oxide top cathode prepared by plasma damage-free sputtering for top-emitting organic light-emitting diodes. Appl. Phys. Lett. 2006, 88, 012103. [CrossRef]

(C) 2019 by the authors. Licensee MDPI, Basel, Switzerland. This article is an open access article distributed under the terms and conditions of the Creative Commons Attribution (CC BY) license (http://creativecommons.org/licenses/by/4.0/). 